\title{
Oral cancer cell-derived exosomes modulate natural killer cell activity by regulating the receptors on these cells
}

\author{
XUEQIN ZHU ${ }^{1,2^{*}}$, XING QIN $^{1,2^{*}}$, XIAONING WANG ${ }^{1,2}$, YINGNAN WANG $^{1,2}$, \\ WEI CAO ${ }^{1,2}$, JIANJUN ZHANG ${ }^{1,2}$ and WANTAO CHEN ${ }^{1,2}$
}

\begin{abstract}
${ }^{1}$ Department of Oral and Maxillofacial-Head and Neck Oncology and Faculty of Oral and Maxillofacial Surgery, Ninth People's Hospital, Shanghai Jiao Tong University School of Medicine; ${ }^{2}$ Shanghai Key Laboratory of Stomatology and Shanghai Research Institute of Stomatology, National Clinical Research Center of Stomatology, Shanghai 200011, P.R. China
\end{abstract}

Received January 15, 2020; Accepted August 19, 2020

DOI: $10.3892 / \mathrm{ijmm} .2020 .4736$

\begin{abstract}
Oral cancer (OC) is the most common type of head and neck malignant tumor. Tumor-derived exosomes induce a complex extracellular environment that affects tumor immunity. In the present study, exosomes were isolated from OC cell lines (WSU-HN4 and SCC-9) by ultrafiltration and the protein content of these oral cancer-derived exosomes (OCEXs) was analyzed by mass spectrometry, which revealed the enrichment of transforming growth factor (TGF)- $\beta 1$. Natural killer (NK) cells were examined by flow cytometry following co-culture with OCEXs. The expression of killer cell lectin like receptor K1 (KLRK1; also known as NKG2D, as used herein) and natural cytotoxicity triggering receptor 3 (NCR3; also known as NKp30, as used herein) in NK cells was found to be significantly upregulated following co-culture with the OCEXs for 1 day, whereas this expression decreased at 7 days. Killer cell lectin like receptor C1 (KLRC1; also known as NKG2A; as used herein) expression exhibited an opposite trend at 1 day. In addition, NK cell cytotoxicity against the OC cells was enhanced at 1 day, but was attenuated at 7 days. TGF- $\beta 1$ inhibited the function of NK cells at 7 days, whereas it had no obvious effects at 1 and 3 days. On the whole, the findings of the present study reveal changes in NK cell function and provide new insight into NK cell dysfunction.
\end{abstract}

Correspondence to: Professor Wantao Chen, Department of Oral and Maxillofacial-Head and Neck Oncology and Faculty of Oral and Maxillofacial Surgery, Ninth People's Hospital, Shanghai Jiao Tong University School of Medicine, 639 Zhizaoju Road, Shanghai 200011, P.R. China

E-mail: chenwantao196323@sjtu.edu.cn

${ }^{*}$ Contributed equally

Key words: oral cancer cells, exosomes, transforming growth factor $\beta 1$, natural killer cells

\section{Introduction}

Head and neck cancer, including oral and oropharyngeal cancer, is the 6th most common malignant tumor worldwide (1). Oral cancer (OC), cancer in the oral cavity and lip, with 300,000 new cases and 145,000-related deaths per year, is a major public health concern globally $(2,3)$. Despite the development of various treatments, the five-year survival rate of patients with $\mathrm{OC}$ has not improved significantly over the past 30 years (4). These daunting statistics emphasize the importance of enhancing the comprehensive understanding of the molecular pathogenesis of OC and the need for the development of effective therapeutic strategies for these patients.

Exosomes are small,lipid-rich, membrane-bound microvesicles with a diameter of $30-150 \mathrm{~nm}$ (5) that are released into the extracellular environment under normal or pathological conditions $(6,7)$. As key microvesicles in cell-cell communications, exosomes contain a large number of biomolecules, such as microRNAs (miRNAs or miRs), proteins and lipids $(8,9)$. Most cell types, including cancer cells, fibroblasts, immune cells and mesenchymal cells have the ability to secrete exosomes. Furthermore, it has been reported that the functional role of exosomes is dependent on the cell of origin (10-12). Numerous studies have demonstrated that tumor cell-derived exosomes (TDEXs) are involved in tumor metastasis, drug resistance and tumor immunity, and are widely distributed in the bodily fluids of cancer patients (13-15). TDEXs are a novel component of the intercellular communication network and play a vital role in the tumor microenvironment (16). Given the diversity of components in TDEXs, the mechanisms through which TDEXs modulate cancer immunity in OC may be complex.

TDEXs reportedly participate in multiple immune mechanisms by interfering with the maturation of dendritic cells (DCs), the function of natural killer (NK) cells and the 'education' of macrophages (17-19). NK cells belong to the innate immune system and can directly kill tumor cells (20). The activity of NK cells is regulated by an array of activating and inhibitory receptors on the cell surface (21). In general, the inhibitory state is dominant during homeostasis $(22,23)$; however, when activating receptors are stimulated, NK cells exert cytotoxic effects and exhibit high levels of antitumor activity (20). NK cells in tumor patients have a reduced level 
of activating receptors, such as natural cytotoxicity triggering receptor 3 (NCR3; also known as NKp30, as used herein), natural cytotoxicity triggering receptor 1 (NCR1; also known as NKp46, as used herein), natural cytotoxicity triggering receptor 2 (NCR2; also known as NKp44, as used herein) and killer cell lectin like receptor K1 (KLRK1; also known as NKG2D, as used herein), which predicts a poor tumor prognosis $(24,25)$. In addition, TDEXs may influence natural antitumor immunity by affecting the quantity and function of NK cells $(26,27)$. Indeed, some studies have demonstrated that TDEXs stimulate the antitumor immunity of NK cells $(18,28,29)$, whereas others have indicated that TDEXs mediate the dysfunction of NK cells through different mechanisms $(30,31)$. Regardless of this, the functional role of OC cell-derived exosomes (OCEXs) in NK cell-mediated antitumor immunity and the underlying mechanisms are far from being fully understood.

In the present study, exosomes were isolated from OC cells and the effects of TDEXs on NK cell activity were investigated. Moreover, the effect of OCEXs on the expression of NK cell receptors were examined and the underlying mechanisms were determined. The findings of the present study may enhance the current understanding of the progression of OCEX-mediated NK cell education.

\section{Materials and methods}

Cells and cell culture. The human OC cell lines, WSU-HN4 (donated by the University of Maryland) and SCC-9 (purchased from ATCC, CRL-1629) were cultured in Dulbecco's modified Eagle's medium (DMEM; Gibco; Thermo Fisher Scientific, Inc.) and DMEM/F-12 (1:1) (basal medium, Gibco; Thermo Fisher Scientific, Inc.), respectively. The human NK cell line NK92MI (purchased from ATCC, CRL-2408) was cultured in RPMI-1640 (basal medium, Gibco; Thermo Fisher Scientific, Inc.). All media were supplemented with $10 \%$ fetal bovine serum (FBS; Bovogen Biologicals Pty Ltd.) and $1 \%$ penicillin-streptomycin (Sigma-Aldrich; Merck KGaA), and all cells were incubated in a humidified incubator with $5 \% \mathrm{CO}_{2}$ at $37^{\circ} \mathrm{C}$. In all OCEX stimulation experiments, OCEXs were co-cultured with NK92MI cells for 1,3 and 7 days. In all transforming growth factor (TGF)- $\beta 1$ stimulation experiments, recombinant human TGF- $\beta 1$ (PeproTech, Inc.) was used at a concentration of $10 \mathrm{ng} / \mathrm{ml}$ for 1,3 and 7 days, as previously described (32-34).

The SCC-9 cells were seeded in a 96-well plate at a density of 1,000 cells per well. Approximately $24 \mathrm{~h}$ later, the tumor cells were co-cultured with the NK92MI cells in medium without FBS and penicillin-streptomycin for $4 \mathrm{~h}$, after which the culture supernatant was removed. The wells were washed gently with PBS and observed under an inverted-phase microscope (Zeiss AG).

Exosome isolation. The steps of exosome isolation and purification were carried out as previously described by Wang et al (28). Briefly, OC cells at $70-80 \%$ confluency were washed 3 times with phosphate-buffered saline (PBS) and cultured in $10 \mathrm{ml}$ of RPMI-1640 without FBS and penicillin-streptomycin for $48 \mathrm{~h}$ at room temperature. Following centrifugation for $10 \mathrm{~min}$ at $3,214 \mathrm{xg}$ at $4^{\circ} \mathrm{C}$, the supernatant was sequentially microfiltered through polyvinylidene fluoride (PVDF) membrane filters of 0.45 and $0.22 \mu \mathrm{m}$ (Merck KGaA) pore size. The flow-through was ultrafiltered through 100-kDa centrifugal filter devices (Merck KGaA). Finally, exosomes in the supernatant were isolated and purified by affinity chromatography using an ExoEasy Maxi kit (Qiagen GmbH). The quality of the obtained OCEX fractions was evaluated by transmission electron microscopy (TEM), nanoparticle tracking analysis (NTA) and western blot analysis.

Transmission electron microscopy observation. The morphology of the OCEXs was assessed by TEM. In brief, the isolated exosomes were dropped onto a copper grid for $10 \mathrm{~min}$, after which $2 \%$ uranyl acetate was deposited onto the copper grid for $1 \mathrm{~min}$. The grid was dried for $10 \mathrm{~min}$ and examined under a transmission electron microscope (FEI Tecnai G2 Spirit, Thermo Fisher Scientific, Inc.).

Nanoparticle tracking analysis. The OCEX size distribution was examined by NTA, which was performed by a Nano Sight NS300 (Malvern Panalytical, Ltd.) equipped with rapid video capture and NTA analytical software. The isolated OCEXs were resuspended in PBS, and the diameter of the particles was detected.

Western blot analysis. OCEXs were lysed using RIPA lysis buffer (Beyotime Institute of Biotechnology, Inc.), and the protein concentrations were measured by a BCA Protein assay (Thermo Fisher Scientific, Inc.). The protein samples were separated on $10 \%$ polyacrylamide gels at $30 \mu \mathrm{g} / \mathrm{well}$ and transferred to PVDF membranes (Merck KGaA). The membranes were blocked in 5\% skim milk at room temperature for $1 \mathrm{~h}$ and incubated with specific primary antibodies at $4^{\circ} \mathrm{C}$ overnight. The membranes were probed with the appropriate horseradish peroxidase (HRP)-conjugated secondary antibodies (ProteinTech Group, Inc.) at room temperature for $1 \mathrm{~h}$. Protein detection was performed with Chemiluminescent HRP Substrate (Merck KGaA), and signals were captured by an Amersham Imager 600 (GE Healthcare). Antibodies against the following proteins were used: CD63 (10628D, mouse monoclonal, $0.5 \mathrm{mg} / \mathrm{ml}, 1: 1,000$, Thermo Fisher Scientific, Inc.), CD9 (10626D, mouse monoclonal, $0.5 \mathrm{mg} / \mathrm{ml}, 1: 500$, Thermo Fisher Scientific, Inc.), Rab5 (A1511-50, rabbit polyclonal, $0.2 \mathrm{mg} / \mathrm{ml}, 1: 500$, Biovision, Inc.) and ALG2-interacting protein (Alix; MA1-83977, mouse monoclonal, $1 \mathrm{mg} / \mathrm{ml}$, 1:500, Thermo Fisher Scientific, Inc.), TGF- $\beta 1$ (21898-1-AP, rabbit polyclonal, $300 \mu \mathrm{g} / \mathrm{ml}, 1: 1,000$, ProteinTech Group, Inc.), $\alpha$-tublin (ab7291, mouse monoclonal, $1 \mathrm{mg} / \mathrm{ml}, 1: 1,000$, Abcam) and GAPDH (10494-1-AP, rabbit polyclonal, $330 \mu \mathrm{g} / \mathrm{ml}, 1: 5,000$, ProteinTech Group, Inc.). Secondary antibodies were as follows: Anti-mouse IgG, HRP-linked antibody (SA0000-1, 1:10,000, Proteintech Group, Inc.), Anti-rabbit IgG, HRP-linked antibody (SA0000-2, 1:10,000, Proteintech Group, Inc.).

Fluorescence microscopy observation. DiO is a lipophilic fluorescent dye with low cytotoxicity that can be used to stain cell membranes and other fat-soluble biological structures. DiO fluorescence is very weak before entering the cell membrane; however, the intensity is greatly enhanced when it is combined 

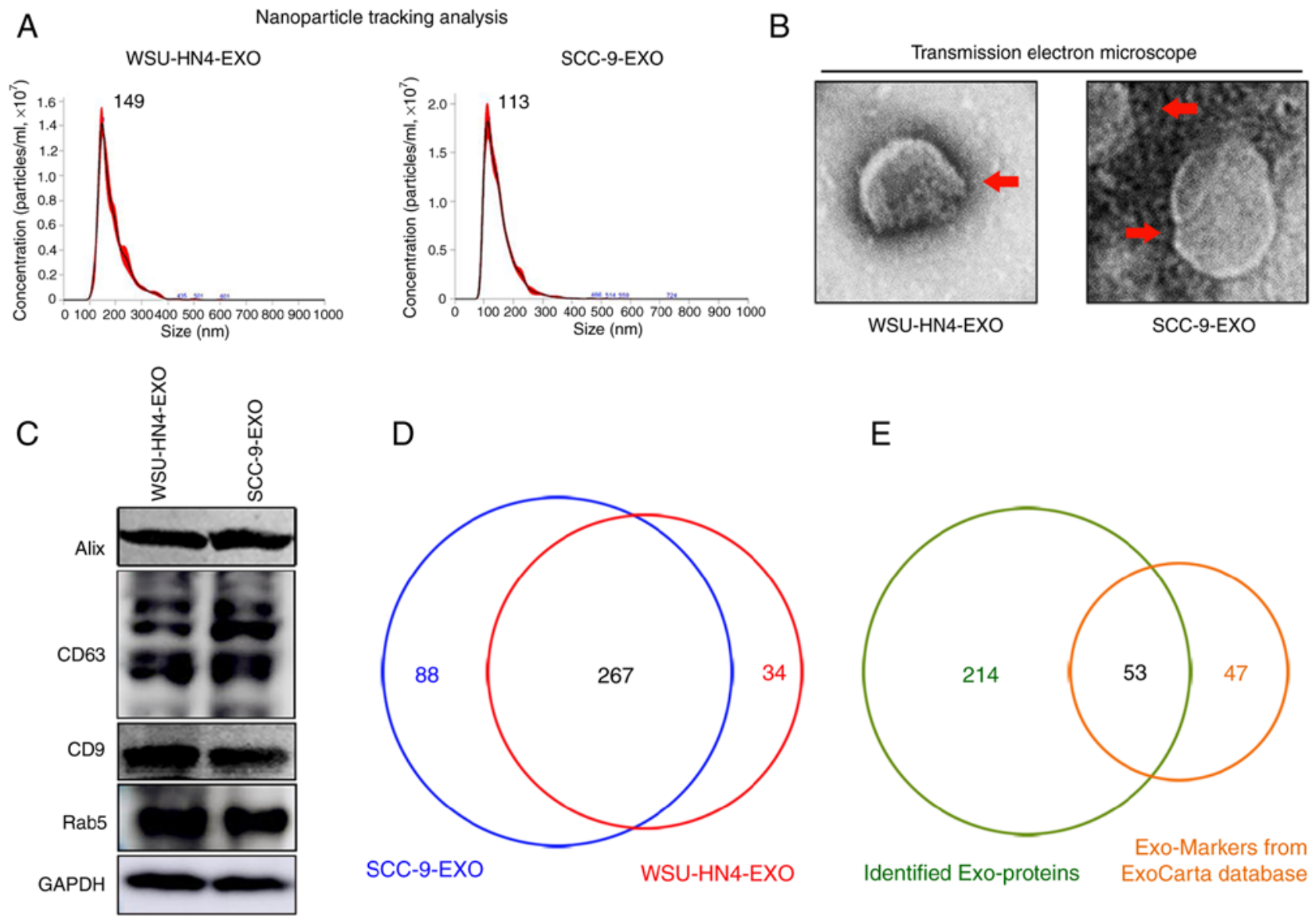

Figure 1. Characterization of OCEXs. (A) The sizes of the WSU-HN4- and SCC-9-derived exosomes were determined by NTA. (B) Representative images of exosomes derived from WSU-HN4 and SCC-9 cells, as detected by TEM. Scale bars, $50 \mathrm{~nm}$. (C) Expression of the exosomal markers, Alix, CD63, CD9 and Rab5, in WSU-HN4- and SCC-9-derived exosomes was determined by western blot analysis. (D) Co-expressed proteins in WSU-HN4- and SCC-9-derived exosomes were detected by mass spectrometry. (E) Overlap of OCEX proteins and the top 100 frequently identified exosomal protein markers from the ExoCarta database. OCEXs, oral cancer-derived exosomes; NTA, nanoparticle tracking analysis; TEM, transmission electron microscopy; EXO/Exo, exosomes.

with the cell membrane and can be detected with standard FITC filters. Exosomes, as typical lipid-rich membrane-bound microvesicles, were fluorescently labeled with DiO. The exosome tracer experiment was implemented with a green fluorescent $\mathrm{DiO}$ cell membrane probe [Yeasen Biotechnology (Shanghai) Co., Ltd.]. The OCEXs were resuspended and incubated with $100 \mu \mathrm{l} \mathrm{DiO}$ working solution at $37^{\circ} \mathrm{C}$ for $20 \mathrm{~min}$. Following incubation with the OCEXs at $37^{\circ} \mathrm{C}$ for $24 \mathrm{~h}$, the NK92MI cells were fixed with $4 \%$ paraformaldehyde at room temperature, stained with TRITC phalloidin [F-actin; Yeasen Biotechnology (Shanghai) Co., Ltd.] and DAPI [Yeasen Biotechnology (Shanghai) Co., Ltd.], and observed under a fluorescence microscope (Zeiss AG).

Cytotoxicity assay. The cytotoxicity of NK92MI cells was determined by a lactate dehydrogenase (LDH) cytotoxicity assay kit (Beyotime Institute of Biotechnology, Inc.). Briefly, the WSU-HN4 or SCC-9 cells were seeded in a 96-well plate at a density of 1,000 cells per well. Approximately $24 \mathrm{~h}$ later, the tumor cells were co-cultured with NK92MI cells in medium without FBS and penicillin-streptomycin for $4 \mathrm{~h}$. The LDH activity of the samples was then detected using a multi-well plate reader (Spectra Max i3, Molecular Devices, LLC) according to the manufacturer's instructions.
Flow cytometric analysis. The expression of surface markers on NK92MI cells was analyzed using a BD FACSCalibur flow cytometer (BD Biosciences). Conjugated fluorescent antibodies were added to an NK92MI single-cell suspension. Following incubation on ice for $15 \mathrm{~min}$ in the dark, the cells were washed twice with PBS and analyzed by flow cytometry. The following fluorochrome-conjugated monoclonal antibodies were used according to the manufacturer's instructions: Anti-NKG2D (cat. no. 558071, clone\# 1D11, HU NKG2D APC MAB, BD Biosciences), anti-NKp30 (cat. no. 558408, clone\# p30-15, HU CD337 ALEXA647 MAB, BD Biosciences), anti-NKp44 (cat. no. 558563, clone\# p44-8, HU NKp44 PE MAB, BD Biosciences), anti-NKp46 (cat. no. 557991, clone\# 9E2/NKp46, HU NKp46 PE MAB, BD Biosciences) and anti-NKG2A (cat. no. FAB1059A, clone\# 131411, hNKG2A APC MAB, R\&D Systems, Inc.).

Mass spectrometry analysis of OCEXs. OCEXs (50 $\mu \mathrm{g})$ of were used for mass spectrometry analyses. The samples were boiled for $10 \mathrm{~min}$ and centrifuged at $14,000 \mathrm{x} \mathrm{g}$ at $4^{\circ} \mathrm{C}$ for $45 \mathrm{~min}$; BCA quantification was performed on the supernatant, which stored at $-80^{\circ} \mathrm{C}$. Subsequently, $40 \mu \mathrm{g}$ per sample was transferred to a new $1.5-\mathrm{ml}$ tube. The samples were prepared with filter-aided proteome preparation (FASP) and separated by 
A

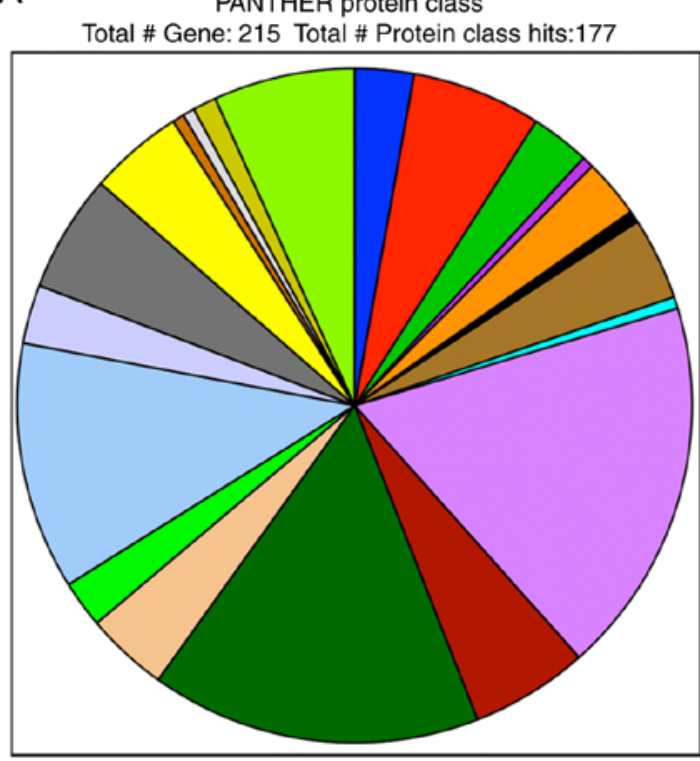

${ }^{* *}$ Chart tooltips are read as: Category name (Accession): \# Percent of gene hit against total

B
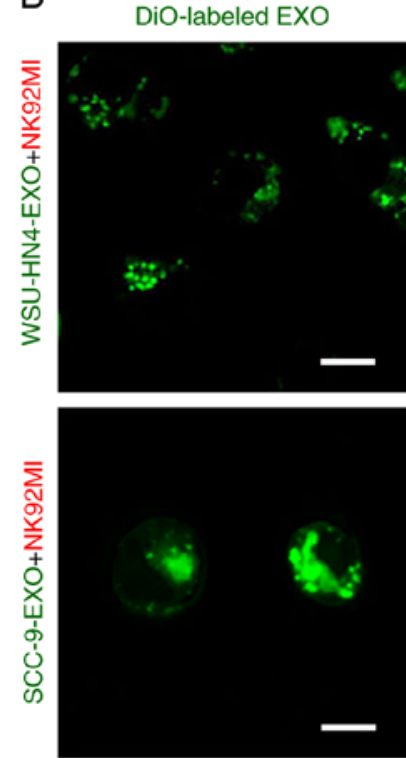

Extracellular matrix protein (PC00102; 2.5\%)

Cytoskeletal protein (PC00085; 5.4\%)

Transporter (PC00227; 2.5\%)

Transmembrane receptor regulatory (PC00226; 0.5\%)

Oxidoreductase (PC00176; $2.5 \%)$

Lyase (PC00144; 0.5\%)

Cell adhesion molecule (PC00069; 3.4\%)

Ligase (PC00142; 0.5\%)

Nucleic acid binding (PC00171; 15.7\%)

Signaling molecule (PC00207; 4.9\%)

Enzyme modulator (PC00095; 13.7\%)

Calcium-binding protein (PC00060; 3.4\%)

Defense/immunity protein (PC00090; $2.0 \%$ )

Hydrolase (PC00121; 10.3\%)

Transfer/carrier protein (PC00219; 2.5\%)

Membrane traffic protein (PC00150; 4.9\%)

Chaperone (PC00072; 3.9\%)

Cell junction protein (PC00070; 0.5\%)

Storage protein (PC00210; 0.5\%)

Isomerase (PC00135; 1.0\%)

Receptor (PC00197; 5.9\%)
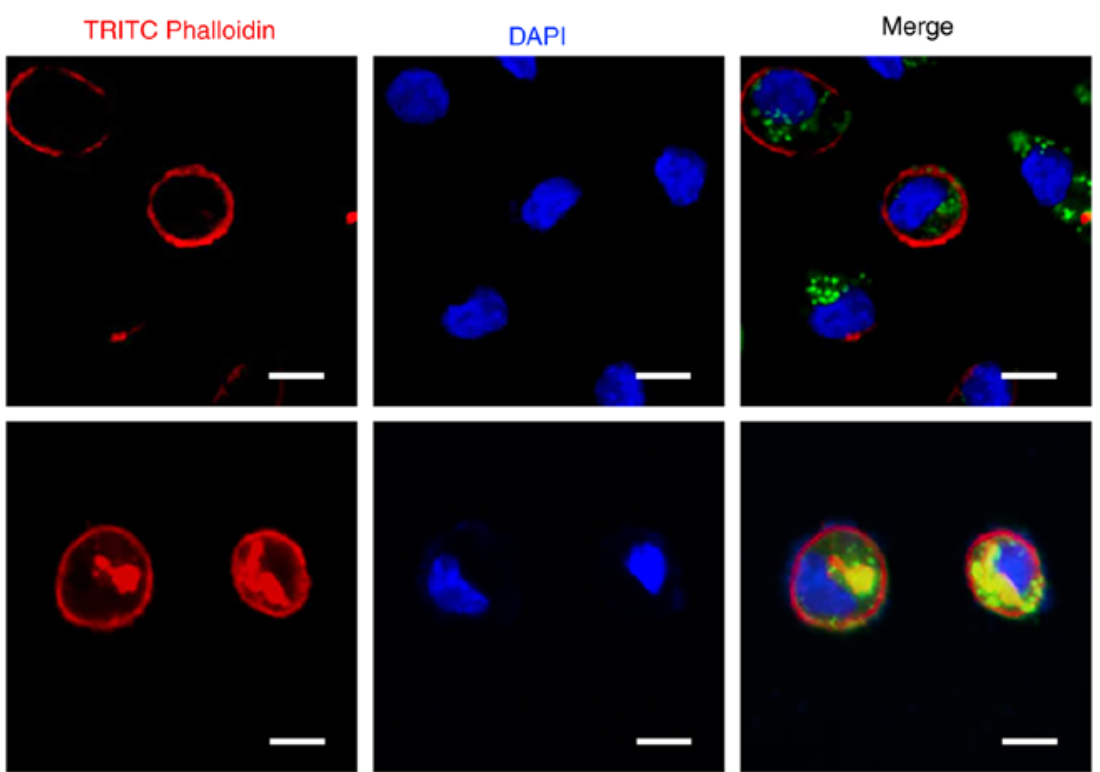

Figure 2. Proteomics analysis of OCEXs. (A) PANTHER protein class analysis of OCEX proteins. (B) For exosomal tracing, NK92MI cells were incubated with DiO-labeled OCEXs for $24 \mathrm{~h}$ followed by fluorescence microscopy. Scale bars, $10 \mu \mathrm{m}$. OCEXs, oral cancer-derived exosomes.

capillary high-performance liquid chromatography (HPLC). The samples were transferred from the automatic sampler to the upper column (EASY column $2 \mathrm{~cm} \times 100 \mu \mathrm{m} \times 5 \mu \mathrm{m}-\mathrm{C} 18$ Thermo Fisher Scientific, Inc.) and separated by the analysis column (EASY column $75 \mu \mathrm{m} \times 100 \mathrm{~mm} \times 3 \mu \mathrm{m}-\mathrm{C} 18$; Thermo Fisher Scientific, Inc.). Thereafter, the samples were analyzed by mass spectrometry with a Q-Exactive mass spectrometer (Thermo Finnigan, LLC). The raw data file was retrieved and analyzed by MaxQuant_1.3.0.5 software.

Functional enrichment analysis of exosomal proteins. In the present study, exosomal markers were provided by ExoCarta databas (http://www.exocarta.org/). An intersection analysis of exosomal markers and the identified exosomal proteins was carried out using the Venn diagrams web tool (http://bioinformatics.psb.ugent.be/webtools/Venn/). Moreover, functional enrichment analyses for Gene Ontology (GO) terms (biological processes, molecular functions and cellular components) and Kyoto Encyclopedia of Genes and Genomes (KEGG) pathway analyses were conducted through the Database for Annotation, Visualization and Integrated Discovery (DAVID) v6.8 (https://david.ncifcrf.gov/), and the data were further developed by using the clusterProfiler package in $\mathrm{R}$ (version 3.6.1). In addition, a functional analysis of these identified exosomal proteins was conducted using the PANTHER protein class analysis (http://geneontology.org/; http://pantherdb.org/). 


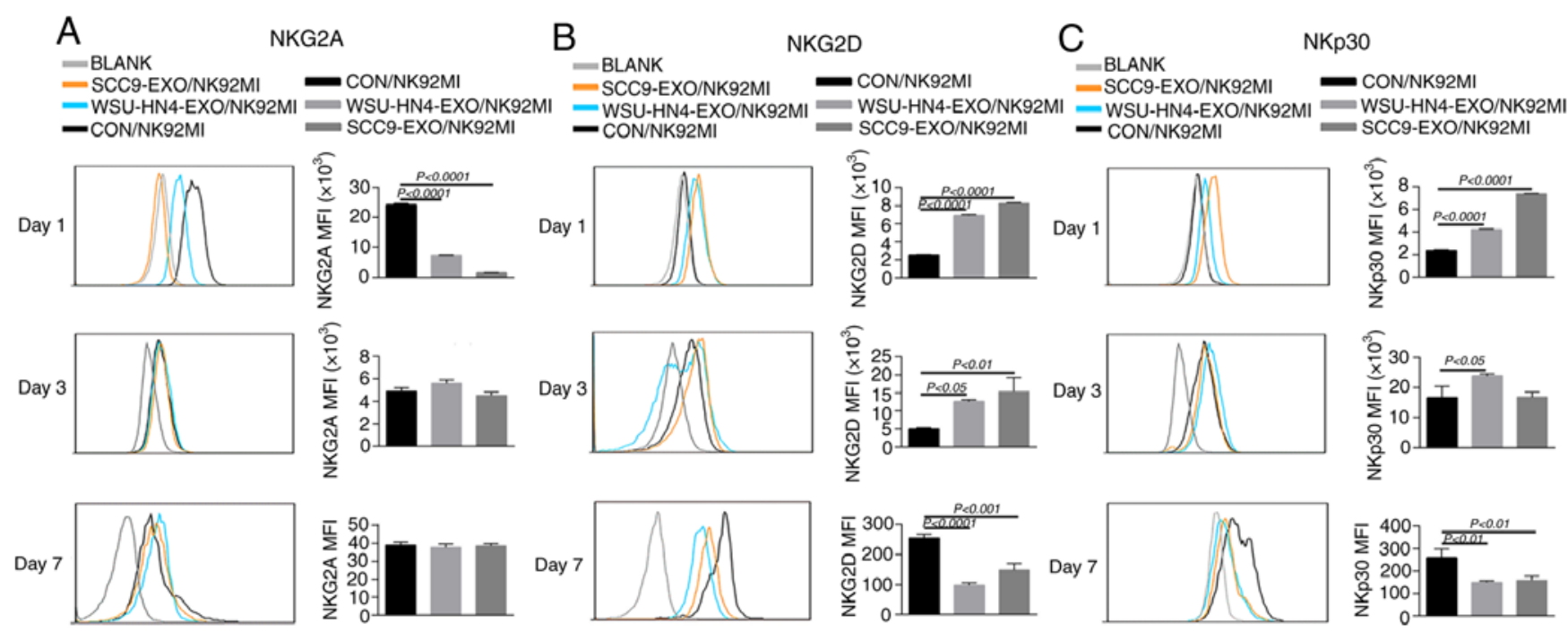

Figure 3. Receptor expression changes in NK cells treated with OCEXs. (A) Expression of NKG2A on NK92MI cells following co-culture with OCEXs for 1, 3 and 7 days. (B) Expression of NKG2D on NK92MI cells following co-culture with OCEXs for 1, 3 and 7 days. (C) Expression of NKp30 on NK92MI cells following co-culture with OCEXs for 1, 3 and 7 days. Receptors on NK92MI cells were detected by flow cytometry. OCEXs, oral cancer-derived exosomes; NK, natural killer.

Statistical analyses. Differences between 3 groups were assessed by one-way ANOVA (with Dunnett's multiple comparisons test) and those between 2 groups were assessed using an unpaired Student's t-test. All statistical analyses were performed using GraphPad Prism 6 (GraphPad Software, Inc.). Data were considered statistically significant when the P-value was $<0.05$.

\section{Results}

Characterization of OCEXs. The OCEXs used in the present study were isolated from cell culture supernatants of OC cells via ultrafiltration, as previously described (28). The morphological characteristics and size of the OCEXs were analyzed by TEM and NTA. The OCEXs exhibited saucer-like particle shapes with membranous structures, when examined by TEM (Fig. 1B), which is consistent with the morphology of exosomes described previously (35). For further accurate diameter detection, the average size of the OCEXs was detected by NTA. The diameters of the exosomes derived from the WSU-HN4 and SCC-9 cells were approximately 149 and $113 \mathrm{~nm}$, respectively (Fig. 1A). Moreover, the common exosomal protein markers, CD63, Rab5, CD9 and Alix, were detected in the OCEXs using western blot analysis (Fig. 1C). Collectively, the above-mentioned data confirmed that the particles isolated from the OC cells were exosomes.

Comprehensive proteomics analysis of OCEXs. The proteomics profile of the OCEXs was analyzed by mass spectrometry. As shown in Fig. 1D, approximately 267 proteins were detected in both the WSU-HN4- and SCC-9-derived exosomes, with a significant overlap between the 2 samples. Moreover, 53 of the top 100 most frequently identified exosomal protein markers according to the ExoCarta database (www.exocarta.org) were detected in the OCEXs, indicating the accuracy of the results (Table SI). Cellular component analysis (https://david.ncifcrf.gov/) was then performed on these 267 identified proteins, and the majority of the identified proteins $(215 / 267)$ were annotated as components of extracellular exosomes (Fig. S1A). To further elucidate the functions of these exosomal proteins, these 215 proteins were subjected to molecular function, biological process and KEGG pathway analyses (https://david.ncifcrf.gov/). The molecular function analysis revealed the enrichment of proteins related to protein binding, protein kinase binding, protein heterodimerization activity, protein domain specific binding, poly(A) RNA binding, identical protein binding, GTP binding, DNA binding, calcium ion binding and cadherin binding and involvement in cell-cell adhesion (Fig. S1B). According to biological process analysis, the proteins in the OCEXs were involved in small GTPase-mediated signal transduction, signal transduction, protein transport, platelet degranulation, nucleosome assembly, negative regulation of apoptotic processes, leukocyte migration, extracellular matrix organization, chromatin silencing and cell adhesion (Fig. S1C). In addition, KEGG pathway analysis revealed the identified proteins to be enriched in alcoholism, systemic lupus erythematosus, pathways in cancer, viral carcinogenesis, endocytosis and the PI3k-Akt signaling pathway, among others, which are closely associated with cancer progression (Fig. S1D). The results of the PANTHER protein class (http://geneontology.org/) analysis revealed that the exosomes derived from the WSU-HN4 and SCC-9 cells contained various types of proteins (Fig. 2A). Among these protein types, transmembrane receptor regulatory proteins (PC00226; 0.5\%), cell adhesion molecules (PC00069; 3.4\%), calcium-binding proteins (PC00060; 3.4\%), membrane traffic proteins (PC00150; 4.9\%) and receptors (PC00197; 5.9\%) have been reported to be associated with exosome uptake, i.e., internalization by recipient cells $(9,36)$. To determine whether OCEXs can be internalized by NK cells, the OCEXs were stained with $\mathrm{DiO}$ (green) and added to the culture medium of NK92MI cells, followed by incubation for $24 \mathrm{~h}$. Under a fluorescence microscope, it was observed that the DiO-labeled OCEXs appeared in the cytoplasm of the NK92MI cells 


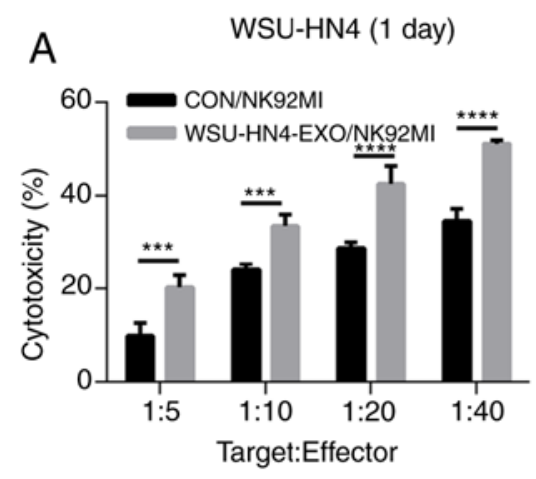

B

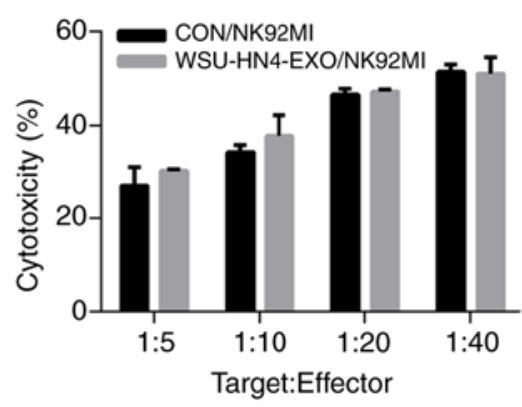

E

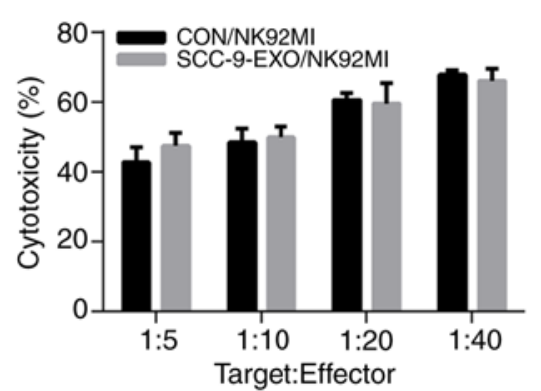

WSU-HN4 (7 days)

C

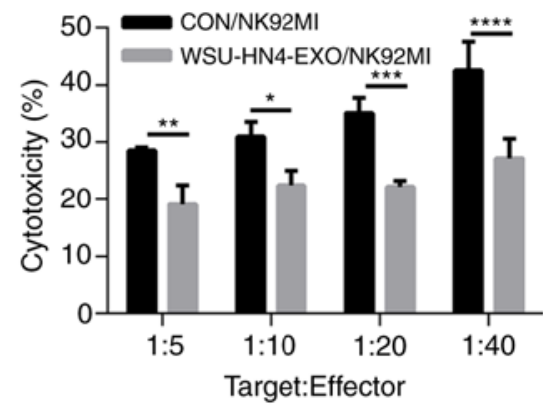

$\mathrm{F}$

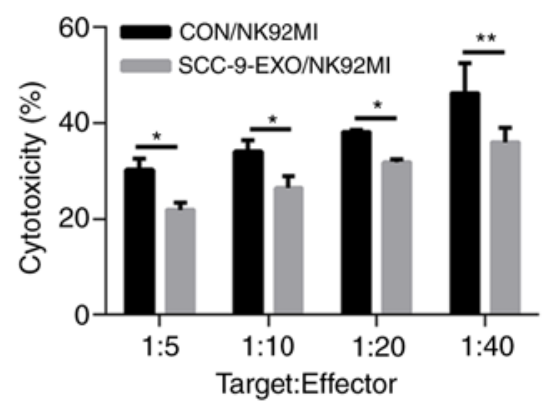

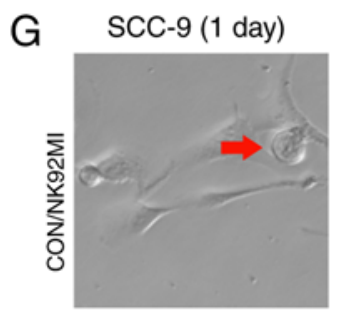

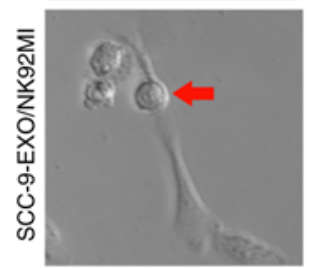

SCC-9 (3 days)
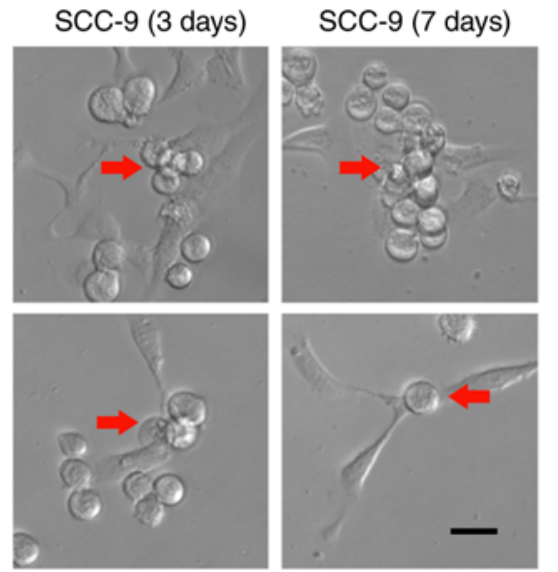

$\mathrm{H}$

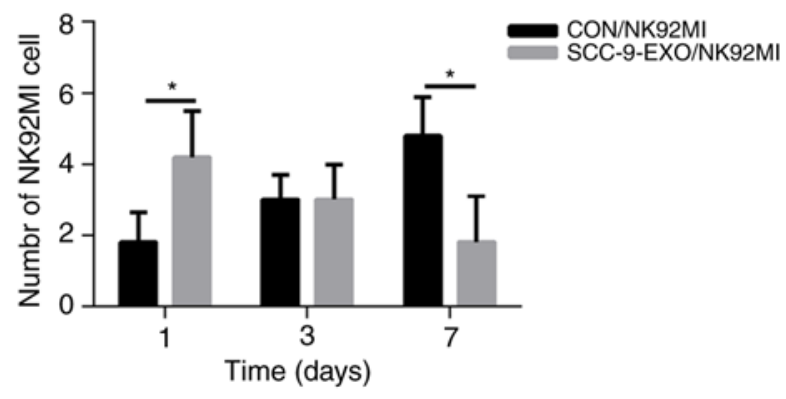

Figure 4. Effect of OCEXs on the cytotoxicity of NK cells. (A-F) Cytotoxicity of NK92MI cells (control and pre-treated with OCEXs) cocultured with OCEXs for 1, 3 and 7 days was analyzed by LDH cytotoxicity assay. Target:Effector indicates the ratio of NK92MI cells to WSU-HN4 or SCC-9 cells. (G and H) The number of adherent NK92MI cells pre-treated with SCC-9-derived exosomes for 1,3 and 7 days. Red arrows indicate NK92MI cells. ${ }^{*} \mathrm{P}<0.05,{ }^{* *} \mathrm{P}<0.01$, ${ }^{* * *} \mathrm{P}<0.001,{ }^{* * * *} \mathrm{P}<0.0001$. Scale bars, $25 \mu \mathrm{m}$. OCEXs, oral cancer-derived exosomes; NK, natural killer.

(Fig. 2B). Taken together, these results indicate that OCEXs are incorporated by NK cells, suggesting their potential role in regulating the functions of NK cells.

Changes in receptor expression on NK92MI cells induced by OCEXs. The function of NK cells is tightly regulated by activating and inhibitory receptors. NKG2D and NKp30, NKp44, NKp46 are important activating receptors on NK cells, and their expression levels are positively associated with their antitumor capacity. Additionally, the expression of NKG2A, one of most important inhibitory receptors of NK cells, is negatively associated with the antitumor activity of NK cells (37). Hence, the present study investigated the effects of OCEXs on NKG2D, NKp30, NKp44, NKp46 and NKG2A expression by treating the NK92MI cells with OCEXs for 1, 3 and 7 days. As a result, the expression of activating receptors (NKG2D, NKp30, NKp44 and
NKp46) on the NK92MI cells was significantly upregulated after 1 day (Figs. 3B and C and S2A and B), whereas the expression of NKG2A was evidently decreased following treatment with the OCEXs for 1 day (Fig. 3A). The above-mentioned data suggest that short-term treatment with OCEXs increases the cytotoxicity of NK cells. Of note, it was found that the expression of activating receptors on NK cells decreased gradually over time, with the expression of the activating receptors, NKG2D, NKp30 and NKp44, diminishing following co-culture with the OCEXs for 7 days (Figs. 3B and C and S2A and B). Conversely, no significant changes in NKG2A expression were observed at 7 days (Fig. 3A). Changes in the cytotoxicity of NK92MI cells induced by OCEXs

To investigate whether the trend of NK cell cytotoxicity was consistent with that of NK cell receptor expression, the NK92MI cells were treated with the OCEXs for 1,3 and 7 days, 
A

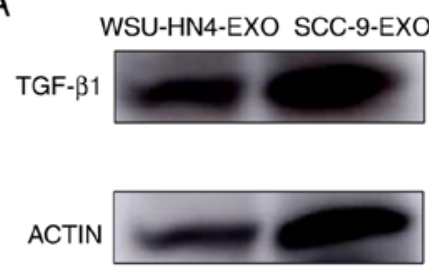

C

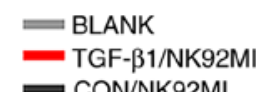

CON/NK92MI
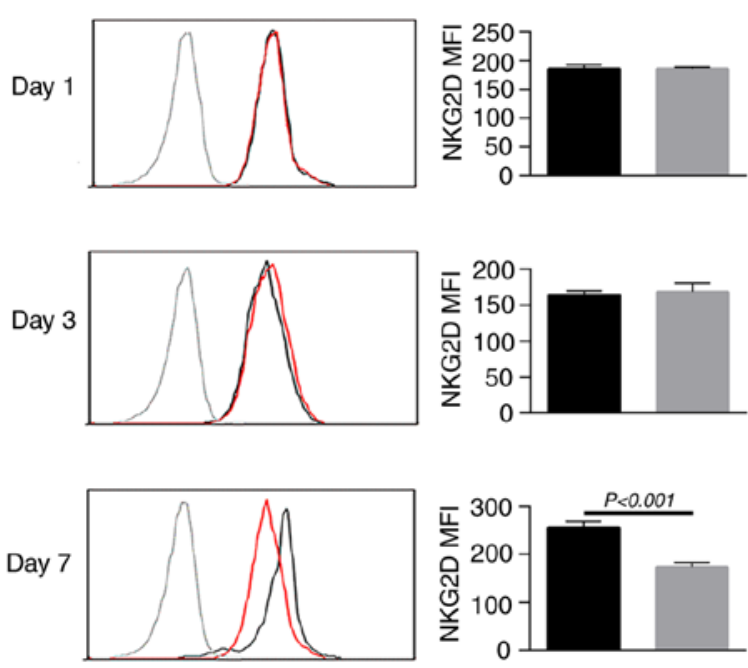

B
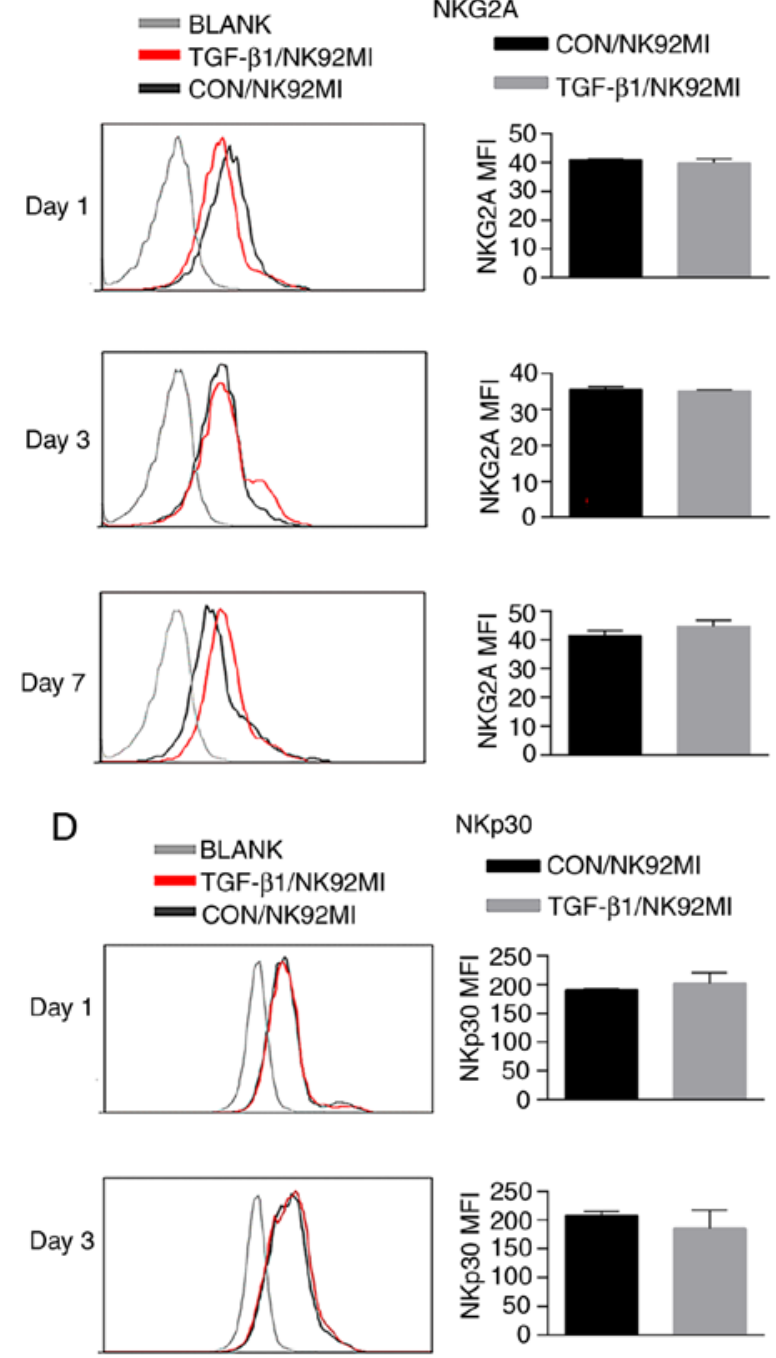

NKG2A
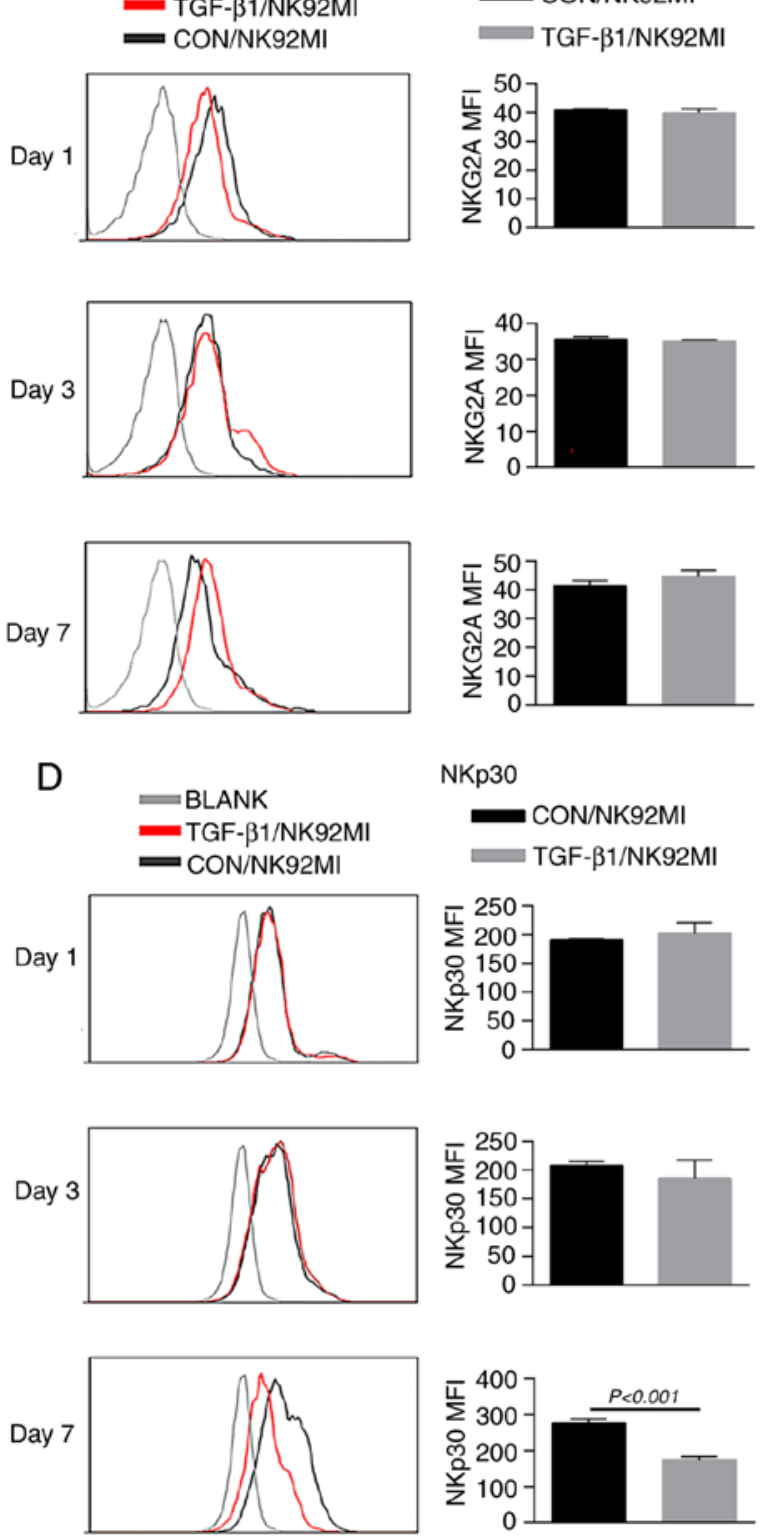

Figure 5. Functional role of TGF- $\beta 1$ in NK cell receptor expression. (A) TGF- $\beta 1$ was expressed in WSU-HN4- and SCC-9-derived exosomes. (B) Expression of NKG2A on NK92MI cells following stimulation with TGF- $\beta 1$ for 1,3 and 7 days. (C) Expression of NKG2D on NK92MI cells stimulated with TGF- $\beta 1$ for 1,3 and 7 days. (D) Expression of NKp30 on NK92MI cells stimulated with TGF- $\beta 1$ for 1, 3 and 7 days. Receptors on NK92MI cells were detected by flow cytometry. NK, natural killer.

and NK92MI cell cytotoxicity was detected by LDH assay. Functionally, the OC cell-killing effect of the NK92MI cells was increased following incubation with the OCEXs for 1 day (Fig. 4A and D). In addition, increased numbers of NK92MI cells attached to the SCC-9 cells were observed at 1 day (Fig. 4G and H). As the OCEX incubation time increased, the cytotoxicity of the NK92MI cells compared to that of the control cells was decreased at 7 days (Fig. 4C and F), and the number of NK92MI cells adhering to the SCC-9 cells was reduced at the same time point (Fig. 4G and $\mathrm{H}$ ). However, there were no clear differences in cytotoxicity between the OCEX-treated and control cells at 3 days (Fig. 4B and E). Hence, the above-mentioned data demonstrated that the OCEXs stimulated NK cytotoxicity at 1 day and this was then inhibited with time up to 7 days.
OCEX-derived TGF- $\beta 1$ inhibits the cytotoxicity of NK cells. TGF- $\beta 1$, a cytokine of the bone morphogenetic protein (BMP)-activin family, participates in a wide range of immune system regulatory processes (38-41). TGF- $\beta 1$ is an acknowledged inhibitory factor of immune system components, including NK cells. In particular, TGF- $\beta 1$ has been reported to reduce the surface expression of crucial activating NK receptors (NKp30 and NKG2D) on NK cells (42). Of note, in the present study, the immunoregulatory factor, TGF- $\beta 1$, was enriched in OCEXs, as determined by mass spectrometric analysis (Table SII), and the expression of TGF- $\beta 1$ in the OCEXs was verified by western blot analysis (Fig. 5A). To further assess the effects of TGF- $\beta 1$ on NK cell activity, NK92MI cells were treated with or without TGF- $\beta 1$ for different periods of time, and expression of NK cell receptors and cytotoxicity were 

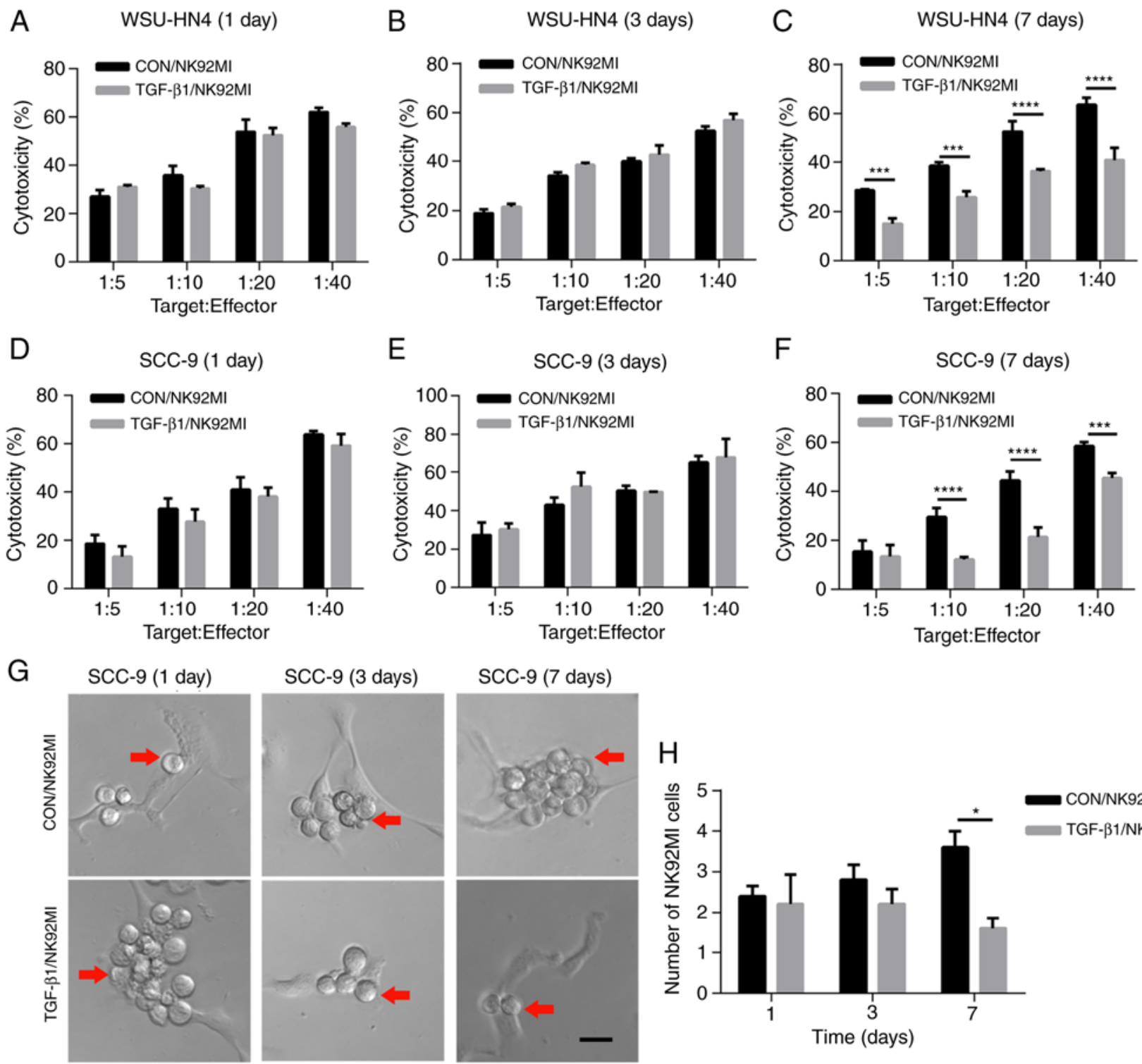

E
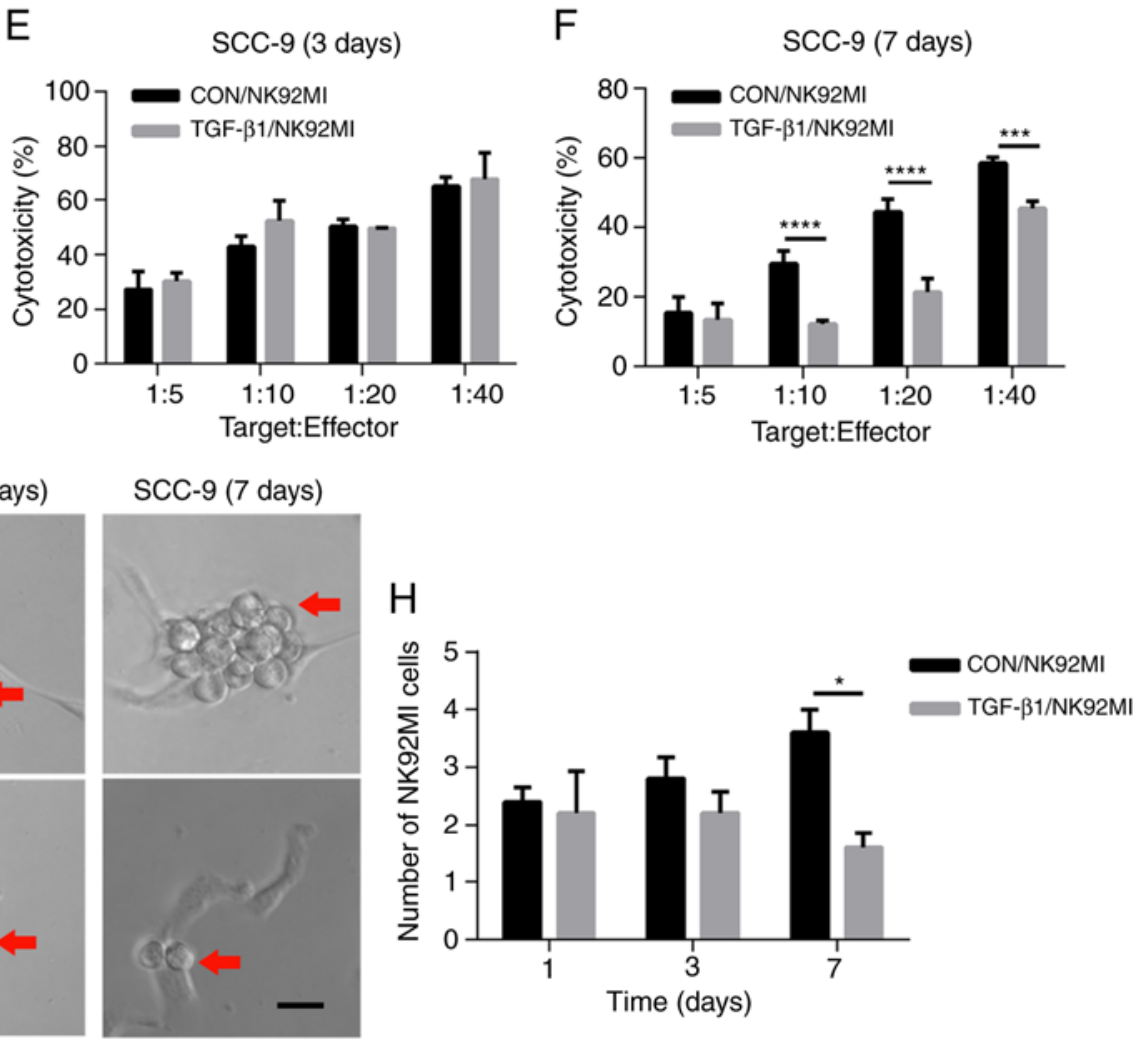

Figure 6. Cytotoxicity of NK cells stimulated with TGF- $\beta 1$. (A-F) The cytotoxicity of NK92MI cells (control and pre-treated with TGF- $\beta 1$ ) treated with TGF- $\beta 1$ for 1, 3 and 7 days was analyzed by LDH cytotoxicity assay. Target:Effect indicates the ratio of NK92MI cells to WSU-HN4 or SCC-9 cells. (G and H) The number of adherent NK92MI cells pre-treated with TGF- $\beta 1$ for 1,3 and 7 days. Red arrows indicate NK92MI cells. ${ }^{*} \mathrm{P}<0.05,{ }^{* * *} \mathrm{P}<0.001,{ }^{* * * * *} \mathrm{P}<0.0001$. Scale bars, $25 \mu \mathrm{m}$. NK, natural killer.

evaluated. There were no obvious changes in receptor expression or cytotoxicity to the NK92MI cells treated with TGF- $\beta 1$ for 1 and 3 days. However, the expression levels of activating receptors (NKp30 and NKG2D) and the cytotoxicity of the TGF- $\beta 1$-treated cells decreased significantly compared to those of the control cells at 7 days (Figs. 5 and 6). However, other receptors (NKp44, NKp46 and NKG2A) exhibited no significant changes in expression (Figs. 5B and S2C and D). Moreover, the number of NK92MI cells attached to the SCC-9 cells was reduced (Fig. 6G and $\mathrm{H}$ ). These findings suggest that OCEXs deliver TGF- $\beta 1$ to NK cells, ultimately resulting in the dysfunction of NK cells.

\section{Discussion}

OC is one of the most lethal malignancies worldwide (2), and the long-term survival rate and prognosis of patients with advanced
OC are poor (43). Therefore, an enhanced understanding of the pathogenesis and mechanisms of OC is warranted. Despite tremendous research advances, the underlying cellular and molecular events involved in OC have yet to be determined. Over the past few decades, exosomes have attracted increasing attention due to their roles in the occurrence and development of tumors. In the present study, OCEXs were isolated from 2 human oral cancer cell lines, WSU-HN4 and SCC-9, by ultrafiltration. Comprehensive proteomics analyses are expected to reveal the potential function of OCEXs. Exosomes are known to carry a variety of cargo, including diverse RNAs, proteins including cytokines, growth factors and lipids (43-45). In the present study, the protein components carried in OCEXs were mainly analyzed by mass spectrometry. The results of PANTHER protein class analysis revealed the significant enrichment of proteins related to localization and biological adhesion, which may promote the ability of OCEXs to adhere 
to the surfaces of recipient cells, fuse with their membranes, and transfer exosomal components to modulate the biological functions of the target cells.

Exosomes are important cellular crosstalk nanovesicles that participate in a number of biological processes (46). In the tumor microenvironment, exosomal contents can be conveyed not only to donor cells but also to different types of immune cells, including NK cells, thus affecting the antitumor immune response $(47,48)$. For example, the antitumor immune responses of NK cells are mediated by the direct killing of cancer cells and cytokine production. NK cell activation is tightly regulated by an interplay between excitatory and inhibitory signals, the latter mainly occurring through NKG2A. NKG2D and natural cytotoxicity receptors, such as NKp30, are potent activating receptors on the surface of NK cells for tumor killing $(37,49)$. It has been reported that heat shock protein (HSP)-bearing exosomes secreted by hepatocellular carcinoma cells enhance the function of NK cells. In this process, the expression of the activating receptors, CD69, NKG2D and NKp44, is upregulated, whereas that of the inhibitory receptor CD94 is downregulated (50). The authors have previously demonstrated that the cytotoxicity of NK cells is temporarily enhanced by OCEXs (28). The results of the present study verified that the short-term incubation of OCEXs with NK cells indeed promoted the function of NK cells. Consequently, when the $\mathrm{NK}$ cells were co-cultured with the OCEXs for 1 day, the upregulated expression of the activating receptors, NKp30 and NKG2D, and the downregulated expression of the inhibitory receptor, NKG2A, were detected. Simultaneously, the cytotoxicity of NK cells was enhanced, and the number of NK cells adhering to cancer cells was increased at 1 day.

Nevertheless, previous studies have demonstrated that TDEXs exert an inhibitory effect on the immune system via NK cells $(30,51)$, and an impaired NK cell function in head and neck, pharyngeal and other solid cancers has been reported. The effects of TDEXs on NK cells may be affected by several factors, such as the cancer cell type, cancer progression stage and the microenvironment $(52,53)$. The results of the present study demonstrated that activating receptor expression decreased with the prolonged incubation of NK cells with OCEXs; the killing function of NK cells also decreased accordingly. These data reveal a change in NK receptor expression, as well as in NK cytotoxicity with increasing OCEX and NK cell incubation times. Thus, the interaction between OCEXs and NK cells increased the tumor-suppressive effects of NK cells in the short-term, whereas it gradually decreased or even reversed the effects, such as cytotoxicity, over time.

The activation of NK cells is dependent on a shift in the signaling balance between inhibitory and activating receptors (37). The factors controlling the capacity of balance between the activating and inhibitory signals have not been fully determined. In the present study, the function of NK cells was ultimately suppressed by prolonged stimulation with OCEXs. To examine the in-depth mechanisms, the levels of proteins in the OCEXs were detected, and TGF- $\beta 1$ was found to be enriched. It has been suggested that patients with head and neck squamous cell carcinoma who exhibit persistently elevated TGF- $\beta 1$ levels following chemoradiotherapy have a poor cancer prognoses (54). In addition, numerous studies have demonstrated that TGF- $\beta 1$ exerts an obvious inhibitory effect on NK cells. When exposed to TGF- $\beta 1$, NK cells may lose the ability to kill cancer cells in humans or mice (55). Studies have also indicated that the level of serum TGF- $\beta 1$ is associated with cancer metastasis and a poor prognosis (56). Therefore, it was hypothesized that the inhibition of NK cell function may be associated with TGF- $\beta 1$ enrichment in OCEXs. In the present study, the inhibitory function of TGF- $\beta 1$ on NK92MI cells at 7 days was verified, and it was found that NK cell function was not significantly altered following stimulation with TGF- $\beta 1$ for 1 and 3 days. Due to the diverse inclusions of exosomes, the effects of OCEXs on NK cells may be complex (57). Our previous study also demonstrated that OCEX-derived NAP1 enhanced cytotoxicity of NK cells (28). In previous studies, NK cell receptor expression has been shown to be altered following co-culture with TGF- $\beta 1$ for 3 days, and NKG2D and NKp30 have been shown to be inhibited $(39,58)$. It is possible that the stimulating effects of TGF- $\beta 1$-treated OCEXs on NK cells may not be evident at first, and gradually become prominent following the extension of the co-culture time. Therefore, it was preliminarily hypothesized that the OCEX-induced NK cell inhibition during 7 days of co-incubation may be related to the enrichment of TGF- $\beta 1$ in OCEXs; nonetheless, the internal mechanisms need to be further explored and investigated. The phenotype of NK cells can be modified by TGF- $\beta 1$. Recently, it was reported that a high TGF- $\beta 1$ expression was associated with a low expression of activating receptors (such as NKG2D and NKp30) on NK cells in the peripheral blood of human cancer patients, which is positively related to disease progression (33). In the present study, the expression of the activating receptors, NKG2D and NKp30, was downregulated in impaired NK cells treated with either OCEXs or TGF- $\beta 1$, suggesting that TGF- $\beta 1$ contained in OCEXs is related to NK cell dysfunction.

In conclusion, the present study found that exosomes derived from OC cells were internalized by NK cells and caused changes in receptor expression on the NK cell surface. Short-term incubation with OCEXs enhanced the function of NK cells, whereas long-term incubation consistently resulted in decreased NK cell cytotoxicity. Further analysis revealed that TGF- $\beta 1$ in OCEXs gradually inhibited NK cell function, deepening the understanding of the mechanisms through which tumor-derived exosomes modulate the functional role of NK cells in the tumor microenvironment. However, it should also be noted that the results of the present study require further confirmation in vivo and further studies are required to identify the specific mechanisms. In addition, whether there are other factors involved in NK cell dysfunction needs to be further explored. Taken together, the findings of the present study provide a different perspective on the important role of exosomes in the immune system, particularly in OCs.

\section{Acknowledgements}

The authors would like to thank Professor Li Mao (Maryland University, USA) for providing the oral cancer cell line, WSU-HN4.

\section{Funding}

The present study was supported by grants from the National Key Research and Development Program of China 
(no. 2016YFC0902700), the National Natural Science Foundation of China (nos. 81874126 and 91229103 and 81672 745), and the Shanghai Science and Technology Commission (no. 18DZ2291500).

\section{Availability of data and materials}

The datasets generated and/or analyzed during the current study are available from the corresponding author on reasonable request.

\section{Authors' contributions}

WCh and JZ made substantial contributions to the conception and design of the study and gave the final approval of the version to be published. XZ and XQ collated the data, performed the data analyses, produced the initial draft of the manuscript and revised it. JZ, WCa, YW and XW participated in collating and analyzing the data. All authors read and approved the final manuscript.

\section{Ethics approval and consent to participate}

Not applicable.

\section{Patient consent for publication}

Not applicable.

\section{Competing interests}

The authors declare that they have no competing interests.

\section{References}

1. Lala M, Chirovsky D, Cheng JD and Mayawala K: Clinical outcomes with therapies for previously treated recur$\mathrm{rent} / \mathrm{metastatic}$ head-and-neck squamous cell carcinoma (R/M HNSCC): A systematic literature review. Oral Oncol 84: 108-120, 2018.

2. Chi AC, Day TA and Neville BW: Oral cavity and oropharyngeal squamous cell carcinoma-an update. CA Cancer J Clin 65: 401-421, 2015.

3. Sasahira T and Kirita T: Hallmarks of cancer-related newly prognostic factors of oral squamous cell carcinoma. Int J Mol Sci 19: $2413,2018$.

4. Warnakulasuriya S: Global epidemiology of oral and oropharyngeal cancer. Oral Oncol 45: 309-316, 2009.

5. Brinton LT, Sloane HS, Kester M and Kelly KA: Formation and role of exosomes in cancer. Cell Mol Life Sci 72: 659-671, 2015.

6. Waldenstrom A and Ronquist G: Role of exosomes in myocardial remodeling. Circ Res 114: 315-324, 2014.

7. Syn N, Wang L, Sethi G, Thiery JP and Goh BC: Exosome-mediated metastasis: From epithelial-mesenchymal transition to escape from immunosurveillance. Trends Pharmacol Sci 37: 606-617, 2016.

8. Allenson K, Castillo J, San Lucas FA, Scelo G, Kim DU, Bernard V, Davis G, Kumar T, Katz M, Overman MJ, et al: High prevalence of mutant KRAS in circulating exosome-derived DNA from early-stage pancreatic cancer patients. Ann Oncol 28: 741-747, 2017.

9. Mathieu M, Martin-Jaular L, Lavieu G and Thery C: Specificities of secretion and uptake of exosomes and other extracellular vesicles for cell-to-cell communication. Nat Cell Biol 21: 9-17, 2019.

10. Liu C, Xu X, Li B, Situ B, Pan W, Hu Y, An T, Yao S and Zheng L: Single-exosome-counting immunoassays for cancer diagnostics. Nano Lett 18: 4226-4232, 2018.
11. Zhang Y, Chopp M, Meng Y, Katakowski M, Xin H, Mahmood A and Xiong Y: Effect of exosomes derived from multipluripotent mesenchymal stromal cells on functional recovery and neurovascular plasticity in rats after traumatic brain injury. J Neurosurg 122: 856-867, 2015.

12. van den Boorn JG, Dassler J, Coch C, Schlee M and Hartmann G: Exosomes as nucleic acid nanocarriers. Adv Drug Deliv Rev 65: 331-335, 2013.

13. Fang T, Lv H, Lv G, Li T, Wang C, Han Q, Yu L, Su B, Guo L, Huang S, et al: Tumor-derived exosomal miR-1247-3p induces cancer-associated fibroblast activation to foster lung metastasis of liver cancer. Nat Commun 9: 191, 2018.

14. Shedden K, Xie XT, Chandaroy P, Chang YT and Rosania GR: Expulsion of small molecules in vesicles shed by cancer cells: Association with gene expression and chemosensitivity profiles. Cancer Res 63: 4331-4337, 2003.

15. Whiteside TL: Exosomes and tumor-mediated immune suppression. J Clin Invest 126: 1216-1223, 2016.

16. Kumar B, Garcia M, Weng L, Jung X, Murakami JL, Hu X, McDonald T, Lin A, Kumar AR, DiGiusto DL, et al: Acute myeloid leukemia transforms the bone marrow niche into a leukemia-permissive microenvironment through exosome secretion. Leukemia 32: 575-587, 2018.

17. Whiteside TL: The effect of tumor-derived exosomes on immune regulation and cancer immunotherapy. Future Oncol 13: 2583-2592, 2017.

18. Li Q, Huang Q, Huyan T, Wang Y, Huang Q and Shi J: Bifacial effects of engineering tumour cell-derived exosomes on human natural killer cells. Exp Cell Res 363: 141-150, 2018.

19. Cai J, Qiao B, Gao N, Lin N and He W: Oral squamous cell carcinoma-derived exosomes promote M2 subtype macrophage polarization mediated by exosome-enclosed miR-29a-3p. Am J Physiol Cell Physiol 316: C731-C740, 2019.

20. Childs RW and Carlsten M: Therapeutic approaches to enhance natural killer cell cytotoxicity against cancer: The force awakens. Nat Rev Drug Discov 14: 487-498, 2015.

21. Guillerey C, Huntington ND and Smyth MJ: Targeting natural killer cells in cancer immunotherapy. Nat Immunol 17: 1025-1036, 2016.

22. Gasser S and Raulet DH: Activation and self-tolerance of natural killer cells. Immunol Rev 214: 130-142, 2006.

23. Raulet DH and Vance RE: Self-tolerance of natural killer cells. Nat Rev Immunol 6: 520-531, 2006.

24. Mamessier E, Sylvain A, Thibult ML, Houvenaeghel G, Jacquemier J, Castellano R, Goncalves A, Andre P, Romagne F, Thibault $\mathrm{G}$, et al: Human breast cancer cells enhance self tolerance by promoting evasion from NK cell antitumor immunity. J Clin Invest 121: 3609-3622, 2011.

25. Pietra G, Manzini C, Rivara S, Vitale M, Cantoni C, Petretto A, Balsamo M, Conte R, Benelli R, Minghelli S, et al: Melanoma cells inhibit natural killer cell function by modulating the expression of activating receptors and cytolytic activity. Cancer Res 72: 1407-1415, 2012.

26. Zhu MC, Xiong P, Li GL and Zhu M: Could lung cancer exosomes induce apoptosis of natural killer cells through the p75NTR-proNGF-sortilin axis? Med Hypotheses 108: 151-153, 2017.

27. Mincheva-Nilsson L and Baranov V: Cancer exosomes and NKG2D receptor-ligand interactions: Impairing NKG2D-mediated cytotoxicity and anti-tumour immune surveillance. Semin Cancer Biol 28: 24-30, 2014.

28. Wang Y, Qin X, Zhu X, Chen W, Zhang J and Chen W: Oral cancer-derived exosomal NAP1 enhances cytotoxicity of natural killer cells via the IRF-3 pathway. Oral Oncol 76: 34-41, 2018.

29. Shoae-Hassani A, Hamidieh AA, Behfar M, Mohseni R, Mortazavi-Tabatabaei SA and Asgharzadeh S: NK cell-derived exosomes from NK cells previously exposed to neuroblastoma cells augment the antitumor activity of cytokine-activated NK cells. J Immunother 40: 265-276, 2017.

30. Berchem G, Noman MZ, Bosseler M, Paggetti J, Baconnais S, Le Cam E, Nanbakhsh A, Moussay E, Mami-Chouaib F, Janji B and Chouaib S: Hypoxic tumor-derived microvesicles negatively regulate NK cell function by a mechanism involving TGF- $\beta$ and miR23a transfer. Oncoimmunology 5: e1062968, 2015.

31. Clayton A, Mitchell JP, Court J, Linnane S, Mason MD and Tabi Z: Human tumor-derived exosomes down-modulate NKG2D expression. J Immunol 180: 7249-7258, 2008.

32. Donatelli SS, Zhou JM, Gilvary DL, Eksioglu EA, Chen X, Cress WD, Haura EB, Schabath MB, Coppola D, Wei S and Djeu JY: TGF- $\beta$-inducible microRNA-183 silences tumor-associated natural killer cells. Proc Natl Acad Sci USA 111: 4203-4208, 2014. 
33. Han B, Mao FY, Zhao YL, Lv YP, Teng YS, Duan M, Chen W, Cheng P, Wang TT, Liang ZY, et al: Altered NKp30, NKp46, NKG2D, and DNAM-1 expression on circulating NK cells is associated with tumor progression in human gastric cancer. J Immunol Res 2018: 6248590, 2018.

34. Viel S, Marçais A, Guimaraes FS, Loftus R, Rabilloud J, Grau M, Degouve S, Djebali S, Sanlaville A, Charrier E, et al: TGF- $\beta$ inhibits the activation and functions of NK cells by repressing the mTOR pathway. Sci Signal 9: ra19, 2016.

35. Contreras-Naranjo JC, Wu HJ and Ugaz VM: Microfluidics for exosome isolation and analysis: Enabling liquid biopsy for personalized medicine. Lab Chip 17: 3558-3577, 2017.

36. Gonda A, Kabagwira J, Senthil GN and Wall NR: Internalization of exosomes through receptor-mediated endocytosis. Mol Cancer Res 17: 337-347, 2019.

37. Chiossone L, Dumas PY, Vienne M and Vivier E: Natural killer cells and other innate lymphoid cells in cancer. Nat Rev Immunol 18: 671-688, 2018.

38. Casu B, Dondero A, Regis S, Caliendo F, Petretto A, Bartolucci M, Bellora F, Bottino C and Castriconi R: Novel immunoregulatory functions of IL-18, an accomplice of TGF- $\beta 1$. Cancers (Basel) 11: 75, 2019.

39. Rouce RH, Shaim H, Sekine T, Weber G, Ballard B, Ku S, Barese C, Murali V, Wu MF, Liu H, et al: The TGF- $\beta$ /SMAD pathway is an important mechanism for NK cell immune evasion in childhood B-acute lymphoblastic leukemia. Leukemia 30: 800-811, 2016.

40. Liénart S, Merceron R, Vanderaa C, Lambert F, Colau D, Stockis J, van der Woning B, De Haard H, Saunders M, Coulie PG, et al: Structural basis of latent TGF- $\beta 1$ presentation and activation by GARP on human regulatory T cells. Science 362: 952-956, 2018

41. Dedobbeleer O, Stockis J, van der Woning B, Coulie PG and Lucas S: Cutting Edge: Active TGF- $\beta 1$ released from GARP/TGF- $\beta 1$ complexes on the surface of stimulated human B lymphocytes increases class-switch recombination and production of IgA. J Immunol 199: 391-396, 2017.

42. Fujii R, Jochems C, Tritsch SR, Wong HC, Schlom J and Hodge JW: An IL-15 superagonist/IL-15R $\alpha$ fusion complex protects and rescues NK cell-cytotoxic function from TGF- $\beta 1$-mediated immunosuppression. Cancer Immunol Immunother 67: 675-689, 2018.

43. Carnielli CM, Macedo CCS, De Rossi T, Granato DC, Rivera C, Domingues RR, Pauletti BA, Yokoo S, Heberle H, Busso-Lopes AF, et al: Combining discovery and targeted proteomics reveals a prognostic signature in oral cancer. Nat Commun 9: 3598, 2018

44. Kourembanas S: Exosomes: Vehicles of intercellular signaling, biomarkers, and vectors of cell therapy. Annu Rev Physiol 77: 13-27, 2015.

45. Filipazzi P, Burdek M, Villa A, Rivoltini L and Huber V: Recent advances on the role of tumor exosomes in immunosuppression and disease progression. Semin Cancer Biol 22: 342-349, 2012.

46. Whiteside TL: Exosome and mesenchymal stem cell cross-talk in the tumor microenvironment. Semin Immunol 35: 69-79, 2018.
47. Théry $\mathrm{C}$, Ostrowski $\mathrm{M}$ and Segura E: Membrane vesicles as conveyors of immune responses. Nat Rev Immunol 9: 581-593, 2009.

48. Li I and Nabet BY: Exosomes in the tumor microenvironment as mediators of cancer therapy resistance. Mol Cancer 18: 32, 2019.

49. Kruse PH, Matta J, Ugolini S and Vivier E: Natural cytotoxicity receptors and their ligands. Immunol Cell Biol 92: 221-229, 2014.

50. Lv LH, Wan YL, Lin Y, Zhang W, Yang M, Li GL, Lin HM, Shang CZ, Chen YJ and Min J: Anticancer drugs cause release of exosomes with heat shock proteins from human hepatocellular carcinoma cells that elicit effective natural killer cell antitumor responses in vitro. J Biol Chem 287: 15874-15885, 2012.

51. Reiners KS, Topolar D, Henke A, Simhadri VR, Kessler J, Sauer M, Bessler M, Hansen HP, Tawadros S, Herling M, et al: Soluble ligands for NK cell receptors promote evasion of chronic lymphocytic leukemia cells from NK cell anti-tumor activity. Blood 121: 3658-3665, 2013.

52. Reiners KS, Dassler J, Coch C and Pogge von Strandmann E: Role of exosomes released by dendritic cells and/or by tumor targets: Regulation of NK cell plasticity. Front Immunol 5: 91, 2014.

53. Habif G, Crinier A, Andre P, Vivier E and Narni-Mancinelli E: Targeting natural killer cells in solid tumors. Cell Mol Immunol 16: 415-422, 2019.

54. Chen JL, Chang CC, Huang YS, Kuo HY, Chen TY, Wang CW, Kuo SH and Lin YL: Persistently elevated soluble MHC class I polypeptide-related sequence A and transforming growth factor- $\beta 1$ levels are poor prognostic factors in head and neck squamous cell carcinoma after definitive chemoradiotherapy. PLoS One 13: e0202224, 2018.

55. Jun E, Song AY, Choi JW, Lee HH, Kim MY, Ko DH, Kang HJ, Kim SW, Bryceson Y, Kim SC and Kim HS: Progressive impairment of NK cell cytotoxic degranulation is associated with TGF- $\beta 1$ deregulation and disease progression in pancreatic cancer. Front Immunol 10: 1354, 2019.

56. Astrom P, Juurikka K, Hadler-Olsen ES, Svineng G, Cervigne NK, Coletta RD, Risteli J, Kauppila JH, Skarp S, Kuttner S, et al: The interplay of matrix metalloproteinase-8, transforming growth factor- $\beta 1$ and vascular endothelial growth factor-C cooperatively contributes to the aggressiveness of oral tongue squamous cell carcinoma. Br J Cancer 117: 1007-1016, 2017.

57. Vulpis E, Soriani A, Cerboni C, Santoni A and Zingoni A: Cancer exosomes as conveyors of stress-induced molecules: New players in the modulation of NK cell response. Int J Mol Sci 20: $611,2019$.

58. Klöß S, Chambron N, Gardlowski T, Arseniev L, Koch J, Esser R, Glienke W, Seitz O and Köhl U: Increased sMICA and TGF $\beta_{1}$ levels in HNSCC patients impair NKG2D-dependent functionality of activated NK cells. Oncoimmunology 4: e1055993, 2015.

This work is licensed under a Creative Commons

Attribution-NonCommercial-NoDerivatives 4.0 International (CC BY-NC-ND 4.0) License. 